\title{
Forebrain Cholinergic Signaling: Wired and Phasic, Not Tonic, and Causing Behavior
}

\author{
(ํ) Martin Sarter and Cindy Lustig \\ Department Psychology \& Neuroscience, University of Michigan, Ann Arbor, Michigan 48109
}

Conceptualizations of cholinergic signaling as primarily spatially diffuse and slow-acting are based largely on measures of extracellular brain ACh levels that require several minutes to generate a single data point. In addition, most such studies inhibited the highly potent catalytic enzyme for ACh, AChE, to facilitate measurement of ACh. Absent such inhibition, AChE limits the presence of ambient ACh and thus renders it unlikely that ACh influences target regions via slow changes in extracellular ACh concentrations. We describe an alternative view by which forebrain signaling in cortex driving cognition is largely phasic (milliseconds to perhaps seconds), and unlikely to be volume-transmitted. This alternative is supported by new evidence from real-time amperometric recordings of cholinergic signaling indicating a specific function of rapid, phasic, transient cholinergic signaling in attentional contexts. Previous neurochemical evidence may be reinterpreted in terms of integrated phasic cholinergic activity that mediates specific behavioral and cognitive operations; this reinterpretation fits well with recent computational models. Optogenetic studies support a causal relationship between cholinergic transients and behavior. This occurs in part via transient-evoked muscarinic receptor-mediated high-frequency oscillations in cortical regions. Such oscillations outlast cholinergic transients and thus link transient ACh signaling with more sustained postsynaptic activity patterns to support relatively persistent attentional biases. Reconceptualizing cholinergic function as spatially specific, phasic, and modulating specific cognitive operations is theoretically powerful and may lead to pharmacologic treatments more effective than those based on traditional views.

Key words: acetylcholine; acetylcholinesterase; transients; amperometry; cognition; neuromodulation

\section{Introduction}

Traditional descriptions of the anatomical organization of the basal forebrain cholinergic projections to telencephalic regions emphasize the hallmarks of a neuromodulatory system. These hallmarks include the presence of a relatively small number of somata in the basal forebrain giving rise to collateralized projections to a relatively large innervation space, a limited topographical organization of these projections, and the presence of extrasynaptic cholinergic receptors. Consequently, theories of cholinergic function have primarily described it in terms of volume transmission and slowly changing (over minutes) extracellular ACh levels (Hasselmo, 1999, 2006; Yu and Dayan, 2002). By these views, ACh acts in a spatially and temporally diffuse way to influence the excitability of widespread cortical target regions and thus primarily modulates global, event- or task trial-independent

\footnotetext{
Received June 6, 2019; revised 0ct. 29, 2019; accepted Nov. 4, 2019.

This work was supported by Public Health Service Grants R01DA045063 and P50NS091856. A preprint of this paper was previously made available (https://www.preprints.org/manuscript/201904.0010/v1). We thank Drs. Peter Dayan (Max Planck Institute for Biological Cybernetics), Howard Gritton (Boston University), William M. Howe (Icahn School of Medicine at Mt. Sinai), and Vinay Parikh (Temple University) for comments on a draft of this paper. The authors declare no competing financial interests.

Correspondence should be addressed to Martin Sarter at msarter@umich.edu or cindy Lustig at clustig@umich.edu.

https://doi.org/10.1523/JNEUROSCl.1305-19.2019

Copyright $\odot 2020$ the authors
}

functions, such as "arousal." The main goal of this article is to critically probe these traditional descriptions, including our own prior interpretations of the evidence (Sarter and Bruno, 1997).

As an alternative, we discuss the evidence in support of the view that cortical ACh can directly and causally modulate specific cognitive-behavioral operations, and that this modulation is implemented via highly phasic and probably largely synaptic signaling. This reconceptualization of ACh signaling integrates diverse levels of analysis of cholinergic functions in rodents, nonhuman primates, and humans with newer computational models, and may lead to more effective psychopharmacological development of procholinergic treatments.

\section{Anatomical foundations of locally specific}

cholinergic signaling

Although early work suggested that cholinergic projections from the basal forebrain had uniform effects throughout the brain, contemporary neuroanatomical research has revealed a heretofore unexpected degree of anatomical and functional parcellation of basal forebrain cholinergic neurons. Anatomical studies in rodents have revealed the presence of $>30$ morphologically defined cell clusters in basal forebrain as well as precise relationships between the afferent and efferent projection patterns of individual cholinergic cell groups. Likewise, in humans, postmortem cytoarchitectonic studies of the basal forebrain, and functional imaging studies analyzing functional 
connectivity between basal forebrain subregions and cortical regions, have begun to demonstrate that cellular subdivisions in the basal forebrain give rise to topographically organized, segregated projections to specific target regions (Zaborszky et al., 2008, 2015a,b; Gielow and Zaborszky, 2017; Huppé-Gourgues et al., 2018; Lean et al., 2019). Combined with anatomical evidence indicating limited axonal collateralization (Price and Stern, 1983), this work suggests that cholinergic neurons can have regionally discrete effects, which, for example, may impact information processing in individual cortical areas and layers (Tingley et al., 2015; e.g., Chavez and $\mathrm{Za}$ borszky, 2017).

In addition to this evidence at the systems level, several aspects of cholinergic microcircuitry support spatially differentiated activity. These include the presence of cholinergic contacts with diverse and regionally specific populations of cortical interneurons (e.g., Xiang et al., 1998; Eggermann and Feldmeyer, 2009; Chen et al., 2015), activity-dependent cholinergic modulation of dendritic computation (e.g., Williams and Fletcher, 2019), and region-specific regulation of cholinergic terminals, in part via heteroreceptors expressed at cholinergic terminals. For example, the presence of nAChRs on thalamic glutamatergic terminals in cortex would allow ACh to selectively amplify the processing of sensory stimuli, whereas cholinergic receptors expressed on corticocortical projections would allow ACh to prioritize the processing of associational information (Hasselmo and Bower, 1992; Lambe et al., 2003; Parikh et al., 2008, 2010; Poorthuis et al., 2013).

On the other hand, electron microscopic examinations of cholinergic varicosities in the cortex found evidence for a synapse at $<15 \%$ of such sites. This suggests predominantly extrasynaptic diffusion of ACh, and thus limited spatial selectivity (Descarries, 1998; Descarries and Mechawar, 2000; Mechawar et al., 2000). Likewise, mAChRs expressed by cortical pyramidal cells were found to be not consistently postsynaptic to cholinergic neurons (Mrzljak et al., 1993; Yamasaki et al., 2010), further suggesting that ACh exerts effects primarily via "volume transmission." This issue is still debated, in part because of conflicting morphological evidence (Umbriaco et al., 1994; Smiley et al., 1997; Descarries and Mechawar, 2000; Turrini et al., 2001).

Conclusive experiments that could demonstrate the presence or absence of volume transmission do not appear straightforward. It is important to note that most of the relevant evidence comes from cortical studies, and our perspective is accordingly limited; differential action in subcortical regions cannot be ruled out. Current evidence suggests potentially multiple modes of cholinergic signaling, and burst firing patterns of basal forebrain cholinergic neurons may support increases in ACh release that last for several seconds (Schneider et al., 1994; Manns et al., 2000; Lee et al., 2005; Puopolo et al., 2005; e.g., Unal et al., 2012). These could potentially support signaling via nonjunctional receptors. As noted by Picciotto et al. (2012), it is difficult to know how far and fast ACh can diffuse from its release site (see also Sarter et al., 2009), and nonjunctional signaling would also require regulatory constraints of the efficacy of AChE (below). A degree of volume transmission would not be inconsistent with our main proposal that ACh mediation of specific behavioral/cognitive operations is primarily phasic (Gulledge and Kawaguchi, 2007; see also Gulledge et al., 2007; Dunant and Gisiger, 2017).

\section{The catalytic power of AChE supports spatially and temporally constrained cholinergic signaling}

The catalytic power of AChE has been called "amazing" and "a hallmark of an evolutionarily perfect enzyme" (Quinn, 1987). Indeed, the rate of ACh hydrolysis is limited by the rate of ACh diffusion to the active site, rather than by how quickly AChE can break it down (Hasinoff, 1982; Antosiewicz et al., 1995; Botti et al., 1999). The regulation of membrane-anchoring of AChE in brain neurons remains poorly understood (but see Perrier et al., 2002). However, AChE is present in dendrites, perikarya, axons, and synaptic clefts (Henderson, 1989), including at the neuromuscular junction (Blotnick-Rubin and Anglister, 2018). It is thus positioned to effectively hydrolyze newly released ACh. Thus, proposals suggesting extrasynaptic presence of "ambient" extracellular ACh levels, capable of reaching targets across tens of micrometers of extracellular space (Descarries, 1998), require mechanisms that limit the synaptic hydrolysis of ACh. Such an escape from hydrolysis has been proposed for ACh released from synapses with relatively large pre to postsynaptic distances, based on the view that AChE is largely bound to presynaptic membranes (Dobbertin et al., 2009). However, the role of neuronally released, soluble forms of AChE (Andres et al., 1990; Appleyard, 1992) in terminating ACh action in vivo would also need to be considered, as would the compensatory role of other esterases capable of hydrolyzing ACh (but see Hartmann et al., 2007). This is especially the case given that knockout of AChE in mice increased brain basal ACh levels from nanomolar to micromolar concentrations but yielded only relatively minor functional impairments (Farar et al., 2012). Our understanding of the regulation of ACh levels by AChE would greatly benefit from evidence indicating, in vivo, whether newly released ACh can escape hydrolysis by endogenous $\mathrm{AChE}$ and thus be available for relatively persistent effects, including at nonsynaptic mAChRs/nAChRs.

We conducted one such test by measuring extracellular choline generation, a main product of ACh hydrolysis, with cholinesensitive electrodes. We also (co)immobilized AChE on these electrodes to hydrolyze ACh that potentially escaped, that is, was not hydrolyzed by, endogenous AChE (Giuliano et al., 2008). In vitro, these electrodes were able to detect nonhydrolyzed ACh at low femtomolar concentrations. In the cortex in vivo, we injected $\mathrm{KCl}$ into the vicinity of the electrodes to produce depolarizationevoked, relatively large increases of ACh release to optimize the possibility some portion of ACh might escape hydrolysis by the endogenous AChE. However, even in such conditions, choline currents did not indicate that any ACh "escaped" the endogenous AChE. In other words, these experiments did not reveal the presence of ACh spared by endogenous AChE. Additional evidence comes from the recent demonstration that electrical stimulation yielded a very limited spread of activated (fluorescent) G-protein-coupled ACh receptors (Jing et al., 2018).

\section{Slow ACh: methodological artifact? New insights from amperometric recordings}

The view that levels of cholinergic neurotransmission can vary across minutes has been supported by evidence associating relatively long-lasting arousal states with different levels of extracellular ACh. For example, hourly microdialysis samples from cortex indicated increases in ACh levels during the active night time of rats (Kametani and Kawamura, 1990; see also Marrosu et al., 1995; JiménezCapdeville and Dykes, 1996). Likewise, our earlier studies using microdialysis to sample, over 6-8 min periods, extracellular cortical ACh levels of attention task-performing rats (e.g., Arnold et al., 2002; St Peters et al., 2011) attributed increased ACh levels to elevated demands on attentional control.

However, microdialysis to collect ACh from the extracellular space typically yields samples containing picomolar to low nanomolar concentrations, close to the detection limit of traditional analytical methods. Thus, most studies reverse-dialyze an AChE 
inhibitor to artificially increase levels of recoverable ACh (Chang et al., 2006; see also Noori et al., 2012). Moreover, it has been necessary to collect samples over several minutes. In other words, ACh levels were considered to vary at the scale of minutes because that was the scale at which they could be measured.

There may be a role for minute-based modulation of subcortical regions involved in likewise slow-changing arousal states. However, experiments using newer methods that allow real-time monitoring of ACh release indicate phasic cortical cholinergic signaling involved in cognitive operations. Amperometric measures of evoked choline currents, which reflect newly released and hydrolyzed ACh (Parikh and Sarter, 2006), revealed phasic, or "transient" cholinergic activity in the PFC of rats performing a signal detection task. Such transients reliably predicted "switch hits": correct signal detections following either a long temporal delay or a perceived nonsignal trial (i.e., after a correct rejection or miss (Parikh et al., 2007; Howe et al., 2013, 2017). These transients did not occur for other trial types, including correct rejections, misses, or hits following other hits.

As discussed previously in detail (Sarter and Kim, 2015; Sarter et al., 2016b), the rise times of cholinergic transients, typically over $0.2-0.5 \mathrm{~s}$ following a transient-evoking stimulus or event, are closely correlated with behavior. In contrast, the relatively delayed, by several seconds, timing of peak amplitudes of choline currents reflects competing cellular processes (production and hydrolysis of ACh vs choline clearance) and thus is unlikely to indicate peak ACh release. Given measurement-related limitations, evidence obtained with electrochemical methods likely cannot be claimed to reveal the "true" temporal resolution of synaptic signaling. Importantly, however, the presence of second-based cholinergic transients, associated with specific behaviors and task trials, as opposed to minute-based changes associated with relatively lasting "arousal" states, indicates that cholinergic transient signaling, at least in cortex, is sufficient to support cognitive operations.

Critically, optogenetic studies (Gritton et al., 2016) demonstrated that cholinergic transients cause behavior: optogenetic inhibition of transients during signal trials reduced hits, but did not affect correct rejections, similar to the effects of cholinergic lesions (McGaughy et al., 1996). Moreover, optogenetic generation of cholinergic transients during cued trials, which therefore coincided with, or substituted the occasional absence of, endogenously generated transients, increased detection rates (or hits). Even more strikingly, optogenetically generated cholinergic transients during noncue (or blank) trials, during which endogenous transients are not observed, drastically increased the rate of false alarms, that is, false claims for the presence of a signal in nonsignal trials, from $\sim 20 \%$ to nearly $50 \%$ (Gritton et al., 2016). We further demonstrated that the behavioral power of cholinergic transients is due to the generation of high-frequency oscillations in cortex that persist beyond the cue period and required muscarinic $\mathrm{M} 1$ acetylcholine receptor $(\mathrm{mAChR}$ ) stimulation (Howe et al., 2017). Thus, fast, phasic and precisely timed presynaptic cholinergic signaling can give rise to relatively long-lasting postsynaptic effects (Hangya et al., 2015; Martinez-Rubio et al., 2018; Urban-Ciecko et al., 2018) (see also Case study 2, below).

These studies demonstrated the presence and behavioral significance of trial-based, transient cholinergic signaling. The precise computation driven by cholinergic transients remains to be fully determined. The task circumstances in which they have been demonstrated thus far, that is, "shift-hits," or signal detection after a long temporal delay or nondetection, suggest two possibilities: importantly, both replace the traditional view describing ACh in terms of slow-acting modulation of behavioral states with specific operations determined by the presence or absence of discrete cholinergic transients.

The first builds on decision theory and describes a noisy and imperfect balance between competitive "signal-absent" and "signalpresent" representations of the current task context (Yu and Dayan, 2005). By this view, the cholinergic transient shifts the excitatory/ suppressive balance away from the dominant "signal-absent" context representation to the "signal-present" one (Schmitz and Duncan, 2018). The triggering of false alarms on signal-absent trials via optogenetically induced transients described above serves as an extreme experimental demonstration of this idea (Gritton et al., 2016).

The second possibility is less focused on the signal per se. Instead, it describes the relevant operations as an early step in (re)activating the currently dormant signal-associated response rules and stimulus-response mappings (i.e., the "task set"). This interpretation is consistent with the observation that, in humans performing the signal-detection task used in the rodent studies, shift-hits primarily activate a prefrontal region associated with switching from externally oriented (monitoring) processes to internal processing (specifically, memory or task-set retrieval) (Burgess et al., 2005; Chun and Johnson, 2011; for additional evidence that the fMRI findings related to shift-hits are cholinergically mediated, see Howe et al., 2013).

\section{Cholinergic "tone": an intuitive, method-derived but unneeded concept?}

As already mentioned, evidence for the traditionally dominant view that ACh acts relatively slowly to influence widespread target regions comes from several sources. The first is evidence obtained using microdialysis to monitor extracellular ACh levels. Data obtained from this method necessarily suggested the functionality of slowly changing levels of cholinergic tone (Savage, 2012; e.g., Coppola et al., 2016; Lecrux et al., 2017). Correlations between slowly changing ACh levels and slowly changing brain (arousal) states (Xu et al., 2015; e.g., Anaclet et al., 2015; Zant et al., 2016; Teles-Grilo Ruivo et al., 2017; Yang et al., 2017) supported the view that variations in "tonic" ACh levels are functional. Furthermore, computational models demonstrated the utility of relatively tonic widespread cholinergic activity in understanding the encoding of information (Hasselmo and McGaughy, 2004; Hasselmo, 2006).

We have already described how the temporal limitations of microdialysis may lead to an artifactual view of cholinergic activity as occurring over long timescales, and the problems that the known efficiency of AChE poses for the view that cholinergic function is spatially and temporally diffuse. Definitive evidence on this point likely awaits further methodological development. Arguing for the alternative view, that the (cortical) cholinergic synapse is equipped to support highly phasic cholinergic signaling, and that this is the primary mechanism supporting cognitive operations, puts the onus on us to explain how phasic signaling measured using amperometric methods could give rise to the apparently longer-timescale activity observed using microdialysis.

A direct test of this possibility has remained elusive. The dimensions of the neurochemical measures obtained from microdialysis versus enzyme-coated microelectrodes and amperometry cannot be readily unified, and the measurement compartments and terminal fields monitored by these two methods differ substantially (e.g., Howe et al., 2017, their Fig. 2). To complicate the issue further, the amperometric method is optimized for the measurement of transients and probably not capable of tracking 
slow changes in ACh (should those exist), largely because hydrolyzed choline spikes are rapidly cleared by cholinergic synapses and also diffuse into the interstitial space.

However, as a first step to testing the possibility that dialysisderived ACh levels represent integrated cholinergic transients, we measured choline currents using amperometry and measured ACh levels using microdialysis in (necessarily separate groups of) rats performing a cued appetitive response task, with long temporal delays between cues (60-120 s). Measures were obtained from PFC and from motor cortex. In this task, amperometrically measured choline spikes occur in trials in which rats behaviorally indicate detection of a cue predicting subsequent reward delivery. To compare amperometric data with ACh levels measured in 8 min dialysate collections, we collapsed transient amplitudes over 8 min periods (Parikh et al., 2007). There was no statistically significant difference between these two datasets, suggesting that microdialysis levels could be reproduced by folding amperometric data into time bins that matched the dialysis collection intervals. The evidence that transient signaling is sufficient to describe forebrain cholinergic signaling is thus tentative but appears to be at least quantitatively possible.

\section{Reinterpretation of cholinergic function in terms of transient signaling: two illustrations}

The evidence in support of relatively low temporal and spatial dynamics of cholinergic signaling and associated brain states is extensive. As noted earlier, this low-resolution form of cholinergic signaling cannot be ruled out. However, to test the heuristic potential of the hypothesis that cortical cholinergic activity involved in cognitive operations is primarily phasic, below we explore whether it could in theory reexplain two classic "case studies" for such low-resolution modulation.

\section{Case 1: REM sleep}

It has been widely accepted that forebrain cholinergic tone is elevated during REM sleep, and that ACh levels in that stage are nearly similar with levels seen in the awake state. Indeed, evidence connecting arousal states to ACh levels has remained a major source of support for the idea of cholinergic tone.

The primary evidence comes from studies that preceded even those using microdialysis. Sealed chambers were placed onto the pial surface of the cortex of anesthetized animals and perfused with AChE inhibitors to prevent ACh hydrolysis. Individual samples were collected over 10-15 min periods. ACh levels in these samples, in response to electrical stimulation of the reticular formation, formed the basis of the notion that arousing events increase cortical ACh levels (Celesia and Jasper, 1966; Szerb, 1967; Phillis, 1968). Subsequent microdialysis studies measured extracellular ACh levels in 5-60 min dialysate samples and confirmed that ACh levels were higher during wakefulness and paradoxical sleep than during slowwave-sleep (Kametani and Kawamura, 1990, 1991; Marrosu et al., 1995; Jiménez-Capdeville and Dykes, 1996).

Using choline-sensitive microelectrodes and amperometry, we sampled cholinergic activity in cortex and hippocampus across all stages of the sleep/wake cycle (Gritton et al., 2009). During REM sleep, the frequency of transients was approximately fourfold higher than during slow-wave sleep ( 0.4 vs 0.1 transients/min), and significantly higher than during wakefulness ( 0.25 transients/min). Furthermore, we observed noncorrelated, or desynchronized, transients at recordings sites that were separated by only $\sim 100 \mu \mathrm{m}$. This suggests that within a neuronal space of $500 \mu \mathrm{m}^{3}$, approximating the space contributing to analyte recovery in microdialysis studies (Dykstra et al., 1992), tran- sients during REM sleep may occur at a rate of over $10-50 / \mathrm{min}$. Such a rate would be robustly higher than the rate observed during behavior (above). It could readily account for the elevated ACh levels seen in studies which used microdialysis or other lowtemporal resolution methods to monitor ACh.

\section{Case 2: cholinergic top-down control: evidence for a relatively "tonic" action of ACh?}

Thus far, our description of the cognitive operations supported by cholinergic transients has focused on shifts from one task or context representation (nonsignal) to another (signal detection). However, successful cognition also requires the ability to maintain stability and stay "on task," especially in the face of distractors or other challenges. The cholinergic system also plays a critical role in this aspect of cognition, one that we and others have previously ascribed to longer-term cholinergic activity.

In rats performing the same signal-detection task used to demonstrate cholinergic transients (above), microdialysis measures of right frontal and parietal ACh levels are elevated relative to pretask baseline. They increase further in the face of a perceptualattentional challenge (changing background illumination) that disrupts performance (St Peters et al., 2011; for additional evidence of the cholinergic system's essential role in responding to challenge, see Gill et al., 2000; Kozak et al., 2006). Humans performing a parallel task show parallel increases in activation along the right middle/inferior frontal gyrus (Demeter et al., 2011; Berry et al., 2017). These increases in ACh levels and activation appear to be more strongly related to attempts to maintain or recover performance following challenges than with successful performance per se (Paolone et al., 2012; see also Gritton et al., 2013). Increased levels of cholinergic activity have thus been described as related to "attentional effort," or the motivated activation of attentional systems to stabilize or recover performance, especially in the face of challenge (for evidence from other investigators and tasks reaching similar conclusions see Passetti et al., 2000; McGaughy et al., 2002; Sarter et al., 2006).

Support for the hypothesis that increased levels of attentional effort are mediated via elevated levels of extracellular ACh also comes from humans with a genetic variant that reduces the capacity of the neuronal choline transporter in vitro (Okuda et al., 2002) and, when expressed in mice, reduces choline clearance in vivo (Donovan et al., 2019). Choline transporter capacity is essential for, and the rate-limiting step of, ACh synthesis and release (for review, see Okuda and Haga, 2003; Ferguson and Blakely, 2004; Sarter and Parikh, 2005). The attentional performance of humans expressing this subcapacity choline transporter variant is impaired in the presence of a distractor, and their attentional performance during a distractor challenge is not associated with the increases in frontal cortical activity typically seen in WT humans (Berry et al., 2014, 2015; Sarter et al., 2016a).

These data would seem to present a strong case for a dissociation between a "shifting" function associated with cholinergic transients and trial-based signal detection, and a "stabilization" function associated with more sustained cholinergic activity and resisting distraction. However, these distinct roles may be mediated by different sites of ACh action rather than differences in the timescale of ACh signaling. As noted earlier, the fMRI activation patterns associated with shift-hits are observed in an anterior PFC region associated with retrieval and turning attention toward internal representations. In contrast, those associated with responding to distraction and other attentional challenges occur along the right middle/inferior frontal gyrus. This region serves as a "hub" for coordinating the neural network-level representation 
of relevant task sets (the rules and stimulus-response mappings appropriate for the current context and goals) (e.g., Braver et al., 2009; Lustig and Sarter, 2016; Berry et al., 2017).

Actively maintaining relevant task sets in working memory is critical for the top-down guidance of behavior in accordance with goals, especially in the face of salient but irrelevant distractors. Maintaining representations in working memory, including taskset representations, does not require persistent neuronal firing, cholinergic or otherwise (Lundqvist et al., 2018; but see counterarguments by Constantinidis et al., 2018). Instead, they can be maintained by shifts in synaptic weights or coordinated variability and oscillatory behavior (Dehaene et al., 1998; Lustig et al., 2005; Sadaghiani et al., 2015; e.g., Schmitz and Duncan, 2018). Explicit activity may only be required during the initial acquisition, to recover the task set after an error, to "protect" the representation in the face of competing inputs (see especially the discussion in Dehaene et al., 1998), or to occasionally "refresh" the representation to counteract degradation in network coherence that would otherwise occur as a result of stochastic variability (Lustig et al., 2009).

Together, these findings outline how phasic signaling could support functions previously attributed to slow-acting neuromodulation and describe the evidence needed to test that idea. Recent computational work demonstrates how cholinergic activity supporting the same fundamental operation (normalization, or shared variability among neurons) can support both stimulusand goal-driven attention by operating at different levels of the cortical hierarchy (Schmitz and Duncan, 2018). By this view, the frequency of cholinergic activity is driven quantitatively by situational needs to refresh the task-set representation in the face of interference, rather than being a qualitatively different physiological "mode" operating at a low-resolution timescale (see also Fiebelkorn and Kastner, 2019). Together with the transienttriggered postsynaptic, mAChR-mediated firing activity, which can be more persistent, this presents potential mechanisms by which phasic presynaptic signaling could support longer-term multitrial of goal-driven behavior (Egorov et al., 2002; for computational models showing cholinergically induced persistent firing, see Fransén et al., 2006; for a neuronal mechanism by which cholinergic transients can induce persistent firing of cortical cells, see Cui and Strowbridge, 2019).

In conclusion, in the last 15 years, mounting evidence has indicated that cholinergic signaling can be both temporally (millisecond to second) and spatially (synaptic) specific. This new evidence challenges traditional views of cholinergic function as primarily slow, spatially diffuse, and primarily mediating global, "state" level function, such as arousal. As noted earlier, those traditional views were based largely on microdialysis evidence with limited temporal resolution, and on studies that inhibited AChE and thus its ability to limit spatial and temporal diffusion. This Dual Perspectives article critiques the evidence for the traditional view and presents the case for an alternative: that forebrain-cortical cholinergic activity is primarily phasic and synaptic, and that it correspondingly mediates and can even trigger trial- or event-specific cognitive operations and behaviors.

One important caveat is that most of the existing evidence for phasic, synaptic, signaling is restricted to cortex. There may still be a role for spatially and temporally diffuse cholinergic signaling in correspondingly low-resolution "state" functions, such as arousal. However, to explore the potential power of a synaptic, phasicfocused framework, we have evaluated how such a framework could at least in principle explain even those longer-lasting effects. Many of the experiments to fully test this idea remain to be done. However, this alternative framework provides a straightforward explanation for, and integration of, the results from studies of rodent models and healthy humans, as well as the deficits and sparing in genetic and patient populations. In particular, the generation of long-lasting cortical oscillations from transient mAChR stimulation fits well with both new computational models of cholinergic function and work from other fields (not examining cholinergic activity specifically) demonstrating that sparse, transient bursts of activity can have long-lasting effects.

In addition to its potential theoretical power, a phasic-focused perspective may have important translational implications. To put it bluntly, cholinergic treatments based on the traditional view have had very limited success. Opening the door to exploring the alternative - drugs that enhance and rescue presynaptic, transient cholinergic signaling and postsynaptic mechanisms may lead to the development of more efficacious treatments and have a significant benefit to patients' lives (Howe et al., 2010; Moran et al., 2018; Uslaner et al., 2018; e.g., Kucinski et al., 2019).

Response from Dual Perspective Companion AuthorsAnita A. Disney and Michael J. Higley

In their companion perspective, Sarter and Lustig argue that the actions of ACh are "highly phasic and probably largely synaptic." We believe this position reflects a misapplication of conventional terms for the spatiotemporal compartmentalization of electrochemical signaling in the brain. Indeed, we argue that oversimplified dichotomies, such as "fast versus slow" and "synaptic versus extrasynaptic," underlie much of the confusion regarding the nature of cholinergic activity. As we discuss for glutamate, a canonical fast synaptic transmitter, multiple spatiotemporal "zones," spanning an underlying signaling continuum, should be considered. One zone corresponds to the synaptic space, is limited to tens to hundreds of nanometers located directly under the site of presynaptic release, and supports signaling over tens of milliseconds. A second zone comprises the nearby extrasynaptic (or perisynaptic) space adjacent to the synapse itself, perhaps extending over a few microns. Signaling here occurs over hundreds of milliseconds to seconds (due to both diffusional and secondmessenger kinetics) and is typified by metabotropic, GPCRmediated transduction. In contrast, a third zone includes diverse extracellular spaces that can be tens to hundreds of microns from a synaptic release site. The chemical composition of these latter areas probably dominates measurements of "basal" transmitter levels or "tone." Importantly, most methods used to assay ACh levels (e.g., dialysis or electrochemistry) use probes whose physical size precludes selective measurement from the smallest of these signaling compartments.

The "fast" signaling referred to by Sarter and Lustig, with rise times of $0.2-0.5 \mathrm{~s}$, is still quite slow relative to canonical fast synaptic transmission (the rise time of an ionotropic glutamatergic current is on the order of a few milliseconds). Furthermore, measures based on direct detection of choline have an ambiguous relationship to any particular zone 
and are highly dependent on AChE activity. As we emphasize in our perspective, little is known about central AChE function, and there are difficulties extrapolating data from the neuromuscular junction to the brain. Importantly, AChE may be less efficient in the first two zones (i.e., the synaptic and perisynatic spaces), in part due to inhibition by high substrate concentration.

Overall, most of the physiological evidence presented by Sarter and Lustig does not distinguish between synaptic and perisynaptic zones. As addressed in both perspectives, anatomical data from varied species strongly suggest that cholinergic synapses exist, with close apposition of presynaptic and postsynaptic sites. However, these contacts certainly do not account for all ACh release sites in the brain. Thus, cholinergic activity most likely reflects a blend of spatiotemporal dynamics that do not neatly fall into a binary classification scheme. We agree that ACh function is not well described as a purely tonic signal, although it also fails to exclusively exhibit the high temporal and spatial precision of ionotropic glutamatergic synaptic transmission. The beauty and complexity of neural organization often lie in its subtlety, and we suggest that a more nuanced description of cholinergic activity provides a unifying perspective into the function of this critically important transmitter system.

\section{References}

Anaclet C, Pedersen NP, Ferrari LL, Venner A, Bass CE, Arrigoni E, Fuller PM (2015) Basal forebrain control of wakefulness and cortical rhythms. Nat Commun 6:8744.

Andres C, el Mourabit M, Stutz C, Mark J, Waksman A (1990) Are soluble and membrane-bound rat brain acetylcholinesterase different? Neurochem Res 15:1065-1072.

Antosiewicz J, Gilson MK, Lee IH, McCammon JA (1995) Acetylcholinesterase: diffusional encounter rate constants for dumbbell models of ligand. Biophys J 68:62-68.

Appleyard ME (1992) Secreted acetylcholinesterase: non-classical aspects of a classical enzyme. Trends Neurosci 15:485-490.

Arnold HM, Burk JA, Hodgson EM, Sarter M, Bruno JP (2002) Differential cortical acetylcholine release in rats performing a sustained attention task versus behavioral control tasks that do not explicitly tax attention. Neuroscience 114:451-460.

Berry AS, Demeter E, Sabhapathy S, English BA, Blakely RD, Sarter M, Lustig C (2014) Disposed to distraction: genetic variation in the cholinergic system influences distractibility but not time-on-task effects. J Cogn Neurosci 26:1981-1991.

Berry AS, Blakely RD, Sarter M, Lustig C (2015) Cholinergic capacity mediates prefrontal engagement during challenges to attention: evidence from imaging genetics. Neuroimage 108:386-395.

Berry AS, Sarter M, Lustig C (2017) Distinct frontoparietal networks underlying attentional effort and cognitive control. J Cogn Neurosci 29:12121225.

Blotnick-Rubin E, Anglister L (2018) Fine localization of acetylcholinesterase in the synaptic cleft of the vertebrate neuromuscular junction. Front Mol Neurosci 11:123.

Botti SA, Felder CE, Lifson S, Sussman JL, Silman I (1999) A modular treatment of molecular traffic through the active site of cholinesterase. Biophys J 77:2430-2450.

Braver TS, Paxton JL, Locke HS, Barch DM (2009) Flexible neural mechanisms of cognitive control within human prefrontal cortex. Proc Natl Acad Sci U S A 106:7351-7356.

Burgess PW, Simons JS, Dumontheil I, Gilbert SJ (2005) The gateway hypothesis of rostral prefrontal cortex (area 10) function. In: Measuring the mind: speed, control, and age (Duncan J, McLeod P, Philips LH, eds), pp 217-248. Oxford: Oxford UP.
Celesia GG, Jasper HH (1966) Acetylcholine released from cerebral cortex in relation to state of activation. Neurology 16:1053-1063.

Chang Q, Savage LM, Gold PE (2006) Microdialysis measures of functional increases in ACh release in the hippocampus with and without inclusion of acetylcholinesterase inhibitors in the perfusate. J Neurochem 97:697-706.

Chavez C, Zaborszky L (2017) Basal forebrain cholinergic-auditory cortical network: primary versus nonprimary auditory cortical areas. Cereb Cortex 27:2335-2347.

Chen N, Sugihara H, Sur M (2015) An acetylcholine-activated microcircuit drives temporal dynamics of cortical activity. Nat Neurosci 18:892-902.

Chun MM, Johnson MK (2011) Memory: enduring traces of perceptual and reflective attention. Neuron 72:520-535.

Constantinidis C, Funahashi S, Lee D, Murray JD, Qi XL, Wang M, Arnsten AFT (2018) Persistent spiking activity underlies working memory. J Neurosci 38:7020-7028.

Coppola JJ, Ward NJ, Jadi MP, Disney AA (2016) Modulatory compartments in cortex and local regulation of cholinergic tone. J Physiol Paris 110:3-9.

Cui ED, Strowbridge BW (2019) Selective attenuation of Ether-a-go-go related $\mathrm{K}(+)$ currents by endogenous acetylcholine reduces spikefrequency adaptation and network correlation. Elife 8:e44954.

Dehaene S, Kerszberg M, Changeux JP (1998) A neuronal model of a global workspace in effortful cognitive tasks. Proc Natl Acad Sci U S A 95:1452914534.

Demeter E, Hernandez-Garcia L, Sarter M, Lustig C (2011) Challenges to attention: a continuous arterial spin labeling (ASL) study of the effects of distraction on sustained attention. Neuroimage 54:1518-1529.

Descarries L (1998) The hypothesis of an ambient level of acetylcholine in the central nervous system. J Physiol Paris 92:215-220.

Descarries L, Mechawar N (2000) Ultrastructural evidence for diffuse transmission by monoamine and acetylcholine neurons of the central nervous system. Prog Brain Res 125:27-47.

Dobbertin A, Hrabovska A, Dembele K, Camp S, Taylor P, Krejci E, Bernard V (2009) Targeting of acetylcholinesterase in neurons in vivo: a dual processing function for the proline-rich membrane anchor subunit and the attachment domain on the catalytic subunit. J Neurosci 29:4519_ 4530.

Donovan E, Avila C, Parikh V, Antcliff A, Blakely RD, Sarter M (2019) Reduced choline clearance in vivo in mice expressing a choline transporter subcapacity variant associated with low attentional control in humans. In: Society for Neuroscience Annual Meeting, Chicago.

Dunant Y, Gisiger V (2017) Ultrafast and slow cholinergic transmission: different involvement of acetylcholinesterase molecular forms. Molecules 22:E1300.

Dykstra KH, Hsiao JK, Morrison PF, Bungay PM, Mefford IN, Scully MM, Dedrick RL (1992) Quantitative examination of tissue concentration profiles associated with microdialysis. J Neurochem 58:931-940.

Eggermann E, Feldmeyer D (2009) Cholinergic filtering in the recurrent excitatory microcircuit of cortical layer 4. Proc Natl Acad Sci U S A 106: $11753-11758$

Egorov AV, Hamam BN, Fransén E, Hasselmo ME, Alonso AA (2002) Graded persistent activity in entorhinal cortex neurons. Nature 420:173178.

Farar V, Mohr F, Legrand M, Lamotte d'Incamps B, Cendelin J, Leroy J, Abitbol M, Bernard V, Baud F, Fournet V, Houze P, Klein J, Plaud B, Tuma J, Zimmermann M, Ascher P, Hrabovska A, Myslivecek J, Krejci E (2012) Near-complete adaptation of the PRiMA knockout to the lack of central acetylcholinesterase. J Neurochem 122:1065-1080.

Ferguson SM, Blakely RD (2004) The choline transporter resurfaces: new roles for synaptic vesicles? Mol Interv 4:22-37.

Fiebelkorn IC, Kastner S (2019) A rhythmic theory of attention. Trends Cogn Sci 23:87-101.

Fransén E, Tahvildari B, Egorov AV, Hasselmo ME, Alonso AA (2006) Mechanism of graded persistent cellular activity of entorhinal cortex layer v neurons. Neuron 49:735-746.

Gielow MR, Zaborszky L (2017) The input-output relationship of the cholinergic basal forebrain. Cell Rep 18:1817-1830.

Gill TM, Sarter M, Givens B (2000) Sustained visual attention performanceassociated prefrontal neuronal activity: evidence for cholinergic modulation. J Neurosci 20:4745-4757.

Giuliano C, Parikh V, Ward JR, Chiamulera C, Sarter M (2008) Increases in 
cholinergic neurotransmission measured by using choline-sensitive microelectrodes: enhanced detection by hydrolysis of acetylcholine on recording sites? Neurochem Int 52:1343-1350.

Gritton HJ, Lee TM, Opp M, Sarter M (2009) Cholinergic neurotransmission during REM sleep: combined electrochemical recordings of cholinergic transients and field potentials challenge an old dogma. In: Society for Neuroscience Annual Meeting, Chicago.

Gritton HJ, Stasiak AM, Sarter M, Lee TM (2013) Cognitive performance as a zeitgeber: cognitive oscillators and cholinergic modulation of the SCN entrain circadian rhythms. PLoS One 8:e56206.

Gritton HJ, Howe WM, Mallory CS, Hetrick VL, Berke JD, Sarter M (2016) Cortical cholinergic signaling controls the detection of cues. Proc Natl Acad Sci U S A 113:E1089-E1097.

Gulledge AT, Kawaguchi Y (2007) Phasic cholinergic signaling in the hippocampus: functional homology with the neocortex? Hippocampus 17:327-332.

Gulledge AT, Park SB, Kawaguchi Y, Stuart GJ (2007) Heterogeneity of phasic cholinergic signaling in neocortical neurons. J Neurophysiol 97: 2215-2229.

Hangya B, Ranade SP, Lorenc M, Kepecs A (2015) Central cholinergic neurons are rapidly recruited by reinforcement feedback. Cell 162: $1155-1168$.

Hartmann J, Kiewert C, Duysen EG, Lockridge O, Greig NH, Klein J (2007) Excessive hippocampal acetylcholine levels in acetylcholinesterasedeficient mice are moderated by butyrylcholinesterase activity. J Neurochem 100:1421-1429.

Hasinoff BB (1982) Kinetics of acetylthiocholine binding to electric eel acetylcholinesterase in glycerol/water solvents of increased viscosity: evidence for a diffusion-controlled reaction. Biochim Biophys Acta 704:52-58.

Hasselmo ME (1999) Neuromodulation: acetylcholine and memory consolidation. Trends Cogn Sci 3:351-359.

Hasselmo ME (2006) The role of acetylcholine in learning and memory. Curr Opin Neurobiol 16:710-715.

Hasselmo ME, Bower JM (1992) Cholinergic suppression specific to intrinsic not afferent fiber synapses in rat piriform (olfactory) cortex. J Neurophysiol 67:1222-1229.

Hasselmo ME, McGaughy J (2004) High acetylcholine levels set circuit dynamics for attention and encoding and low acetylcholine levels set dynamics for consolidation. Prog Brain Res 145:207-231.

Henderson Z (1989) Acetylcholinesterase on the dendrites of central cholinergic neurons: an electron microscopical study in the ferret. Neuroscience 28:95-108.

Howe WM, Ji J, Parikh V, Williams S, Mocaër E, Trocmé-Thibierge C, Sarter M (2010) Enhancement of attentional performance by selective stimulation of alpha4beta2* nAChRs: underlying cholinergic mechanisms. Neuropsychopharmacology 35:1391-1401.

Howe WM, Berry AS, Francois J, Gilmour G, Carp JM, Tricklebank M, Lustig C, Sarter M (2013) Prefrontal cholinergic mechanisms instigating shifts from monitoring for cues to cue-guided performance: converging electrochemical and fMRI evidence from rats and humans. J Neurosci 33: $8742-8752$.

Howe WM, Gritton HJ, Lusk NA, Roberts EA, Hetrick VL, Berke JD, Sarter M (2017) Acetylcholine release in prefrontal cortex promotes gamma oscillations and theta-gamma coupling during cue detection. J Neurosci 37: 3215-3230.

Huppé-Gourgues F, Jegouic K, Vaucher E (2018) Topographic organization of cholinergic innervation from the basal forebrain to the visual cortex in the rat. Front Neural Circuits 12:19.

Jiménez-Capdeville ME, Dykes RW (1996) Changes in cortical acetylcholine release in the rat during day and night: differences between motor and sensory areas. Neuroscience 71:567-579.

Jing M, Zhang P, Wang G, Feng J, Mesik L, Zeng J, Jiang H, Wang S, Looby JC, Guagliardo NA, Langma LW, Lu J, Zuo Y, Talmage DA, Role LW, Barrett PQ, Zhang LI, Luo M, Song Y, Zhu JJ, et al. (2018) A genetically encoded fluorescent acetylcholine indicator for in vitro and in vivo studies. Nat Biotechnol 36:726-737.

Kametani H, Kawamura H (1990) Alterations in acetylcholine release in the rat hippocampus during sleep-wakefulness detected by intracerebral dialysis. Life Sci 47:421-426.

Kametani H, Kawamura H (1991) Circadian rhythm of cortical acetylcholine release as measured by in vivo microdialysis in freely moving rats. Neurosci Lett 132:263-266.
Kozak R, Bruno JP, Sarter M (2006) Augmented prefrontal acetylcholine release during challenged attentional performance. Cereb Cortex 16:9-17.

Kucinski A, Phillips KB, Koshy Cherian A, Sarter M (2019) Rescuing the attentional performance of rats with cholinergic losses by the M1 positive allosteric modulator TAK-071. Psychopharmacology. Advance online publication. Retrieved October 16, 2019. doi: 10.1007/s00213-019-05354-5.

Lambe EK, Picciotto MR, Aghajanian GK (2003) Nicotine induces glutamate release from thalamocortical terminals in prefrontal cortex. Neuropsychopharmacology 28:216-225.

Lean GA, Liu YJ, Lyon DC (2019) Cell type specific tracing of the subcortical input to primary visual cortex from the basal forebrain. J Comp Neurol 527:589-599.

Lecrux C, Sandoe CH, Neupane S, Kropf P, Toussay X, Tong XK, LacalleAurioles M, Shmuel A, Hamel E (2017) Impact of altered cholinergic tones on the neurovascular coupling response to whisker stimulation. J Neurosci 37:1518-1531.

Lee MG, Hassani OK, Alonso A, Jones BE (2005) Cholinergic basal forebrain neurons burst with theta during waking and paradoxical sleep. J Neurosci 25:4365-4369.

Lundqvist M, Herman P, Miller EK (2018) Working memory: delay activity, yes! Persistent activity? Maybe not. J Neurosci 38:7013-7019.

Lustig C, Sarter M (2016) Attention and the cholinergic system: relevance to schizophrenia. Curr Top Behav Neurosci 28:327-362.

Lustig C, Matell MS, Meck WH (2005) Not "just" a coincidence: frontalstriatal interactions in working memory and interval timing. Memory 13:441-448.

Lustig C, Shah P, Seidler R, Reuter-Lorenz PA (2009) Aging, training, and the brain: a review and future directions. Neuropsychol Rev 19:504-522.

Manns ID, Alonso A, Jones BE (2000) Discharge profiles of juxtacellularly labeled and immunohistochemically identified GABAergic basal forebrain neurons recorded in association with the electroencephalogram in anesthetized rats. J Neurosci 20:9252-9263.

Marrosu F, Portas C, Mascia MS, Casu MA, Fà M, Giagheddu M, Imperato A, Gessa GL (1995) Microdialysis measurement of cortical and hippocampal acetylcholine release during sleep-wake cycle in freely moving cats. Brain Res 671:329-332.

Martinez-Rubio C, Paulk AC, McDonald EJ, Widge AS, Eskandar EN (2018) Multi-modal encoding of novelty, reward, and learning in the primate nucleus basalis of Meynert. J Neurosci 38:1942-1958.

McGaughy J, Kaiser T, Sarter M (1996) Behavioral vigilance following infusions of $192 \mathrm{IgG}$-saporin into the basal forebrain: selectivity of the behavioral impairment and relation to cortical AChE-positive fiber density. Behav Neurosci 110:247-265.

McGaughy J, Dalley JW, Morrison CH, Everitt BJ, Robbins TW (2002) Selective behavioral and neurochemical effects of cholinergic lesions produced by intrabasalis infusions of 192 IgG-saporin on attentional performance in a five-choice serial reaction time task. J Neurosci 22:19051913.

Mechawar N, Cozzari C, Descarries L (2000) Cholinergic innervation in adult rat cerebral cortex: a quantitative immunocytochemical description. J Comp Neurol 428:305-318.

Moran SP, Dickerson JW, Cho HP, Xiang Z, Maksymetz J, Remke DH, Lv X, Doyle CA, Rajan DH, Niswender CM, Engers DW, Lindsley CW, Rook JM, Conn PJ (2018) M1-positive allosteric modulators lacking agonist activity provide the optimal profile for enhancing cognition. Neuropsychopharmacology 43:1763-1771.

Mrzljak L, Levey AI, Goldman-Rakic PS (1993) Association of m1 and m2 muscarinic receptor proteins with asymmetric synapses in the primate cerebral cortex: morphological evidence for cholinergic modulation of excitatory neurotransmission. Proc Natl Acad Sci U S A 90:5194-5198.

Noori HR, Fliegel S, Brand I, Spanagel R (2012) The impact of acetylcholinesterase inhibitors on the extracellular acetylcholine concentrations in the adult rat brain: a meta-analysis. Synapse 66:893-901.

Okuda T, Haga T (2003) High-affinity choline transporter. Neurochem Res 28:483-488.

Okuda T, Okamura M, Kaitsuka C, Haga T, Gurwitz D (2002) Single nucleotide polymorphism of the human high affinity choline transporter alters transport rate. J Biol Chem 277:45315-45322.

Paolone G, Lee TM, Sarter M (2012) Time to pay attention: attentional performance time-stamped prefrontal cholinergic activation, diurnality, and performance. J Neurosci 32:12115-12128. 
Parikh V, Sarter M (2006) Cortical choline transporter function measured in vivo using choline-sensitive microelectrodes: clearance of endogenous and exogenous choline and effects of removal of cholinergic terminals. J Neurochem 97:488-503.

Parikh V, Kozak R, Martinez V, Sarter M (2007) Prefrontal acetylcholine release controls cue detection on multiple timescales. Neuron 56:141154.

Parikh V, Man K, Decker MW, Sarter M (2008) Glutamatergic contributions to nicotinic acetylcholine receptor agonist-evoked cholinergic transients in the prefrontal cortex. J Neurosci 28:3769-3780.

Parikh V, Ji J, Decker MW, Sarter M (2010) Prefrontal beta2 subunitcontaining and alpha7 nicotinic acetylcholine receptors differentially control glutamatergic and cholinergic signaling. J Neurosci 30:3518-3530.

Passetti F, Dalley JW, O'Connell MT, Everitt BJ, Robbins TW (2000) Increased acetylcholine release in the rat medial prefrontal cortex during performance of a visual attentional task. Eur J Neurosci 12:3051-3058.

Perrier AL, Massoulié J, Krejci E (2002) PRiMA: the membrane anchor of acetylcholinesterase in the brain. Neuron 33:275-285.

Phillis JW (1968) Acetylcholine release from the cerebral cortex: its role in cortical arousal. Brain Res 7:378-389.

Picciotto MR, Higley MJ, Mineur YS (2012) Acetylcholine as a neuromodulator: cholinergic signaling shapes nervous system function and behavior. Neuron 76:116-129.

Poorthuis RB, Bloem B, Verhoog MB, Mansvelder HD (2013) Layerspecific interference with cholinergic signaling in the prefrontal cortex by smoking concentrations of nicotine. J Neurosci 33:4843-4853.

Price JL, Stern R (1983) Individual cells in the nucleus basalis-diagonal band complex have restricted axonal projections to the cerebral cortex in the rat. Brain Res 269:352-356.

Puopolo M, Hochstetler SE, Gustincich S, Wightman RM, Raviola E (2005) Extrasynaptic release of dopamine and volume transmission in the retina. In: Dendritic neurotransmitter release (Ludwig M, ed), pp 175-189. New York: Springer.

Quinn DM (1987) Acetylcholinesterase: enzyme structure, reaction dynamics, and virtual transition states. Chem Rev 87:955-979.

Sadaghiani S, Poline JB, Kleinschmidt A, D’Esposito M (2015) Ongoing dynamics in large-scale functional connectivity predict perception. Proc Natl Acad Sci U S A 112:8463-8468.

Sarter M, Bruno JP (1997) Cognitive functions of cortical acetylcholine: toward a unifying hypothesis. Brain Res Brain Res Rev 23:28-46.

Sarter M, Kim Y (2015) Interpreting chemical neurotransmission in vivo: techniques, time scales, and theories. ACS Chem Neurosci 6:8-10.

Sarter M, Parikh V (2005) Choline transporters, cholinergic transmission and cognition. Nat Rev Neurosci 6:48-56.

Sarter M, Gehring WJ, Kozak R (2006) More attention must be paid: the neurobiology of attentional effort. Brain Res Rev 51:155-160.

Sarter M, Parikh V, Howe WM (2009) Phasic acetylcholine release and the volume transmission hypothesis: time to move on. Nat Rev Neurosci 10:383-390.

Sarter M, Lustig C, Blakely RD, Koshy Cherian A (2016a) Cholinergic genetics of visual attention: human and mouse choline transporter capacity variants influence distractibility. J Physiol Paris 110:10-18.

Sarter M, Lustig C, Berry AS, Gritton H, Howe WM, Parikh V (2016b) What do phasic cholinergic signals do? Neurobiol Learn Mem 130:135-141.

Savage LM (2012) Sustaining high acetylcholine levels in the frontal cortex, but not retrosplenial cortex, recovers spatial memory performance in a rodent model of diencephalic amnesia. Behav Neurosci 126:226-236.

Schmitz TW, Duncan J (2018) Normalization and the cholinergic microcircuit: a unified basis for attention. Trends Cogn Sci 22:422-437.

Schneider JS, Rothblat DS, DiStefano L (1994) Volume transmission of dopamine over large distances may contribute to recovery from experimental parkinsonism. Brain Res 643:86-91.

Smiley JF, Morrell F, Mesulam MM (1997) Cholinergic synapses in human cerebral cortex: an ultrastructural study in serial sections. Exp Neurol 144:361-368.
St Peters M, Demeter E, Lustig C, Bruno JP, Sarter M (2011) Enhanced control of attention by stimulating mesolimbic-corticopetal cholinergic circuitry. J Neurosci 31:9760-9771.

Szerb JC (1967) Cortical acetylcholine release and electroencephalographic arousal. J Physiol 192:329-343.

Teles-Grilo Ruivo LM, Baker KL, Conway MW, Kinsley PJ, Gilmour G, Phillips KG, Isaac JT, Lowry JP, Mellor JR (2017) Coordinated acetylcholine release in prefrontal cortex and hippocampus is associated with arousal and reward on distinct timescales. Cell Rep 18:905-917.

Tingley D, Alexander AS, Quinn LK, Chiba AA, Nitz DA (2015) Cell assemblies of the basal forebrain. J Neurosci 35:2992-3000.

Turrini P, Casu MA, Wong TP, De Koninck Y, Ribeiro-da-Silva A, Cuello AC (2001) Cholinergic nerve terminals establish classical synapses in the rat cerebral cortex: synaptic pattern and age-related atrophy. Neuroscience 105:277-285.

Umbriaco D, Watkins KC, Descarries L, Cozzari C, Hartman BK (1994) Ultrastructural and morphometric features of the acetylcholine innervation in adult rat parietal cortex: an electron microscopic study in serial sections. J Comp Neurol 348:351-373.

Unal CT, Golowasch JP, Zaborszky L (2012) Adult mouse basal forebrain harbors two distinct cholinergic populations defined by their electrophysiology. Front Behav Neurosci 6:21.

Urban-Ciecko J, Jouhanneau JS, Myal SE, Poulet JFA, Barth AL (2018) Precisely timed nicotinic activation drives SST inhibition in neocortical circuits. Neuron 97:611-625.e5.

Uslaner JM, Kuduk SD, Wittmann M, Lange HS, Fox SV, Min C, Pajkovic N, Harris D, Cilissen C, Mahon C, Mostoller K, Warrington S, Beshore DC (2018) Preclinical to human translational pharmacology of the novel M1 positive allosteric modulator MK-7622. J Pharmacol Exp Ther 365:556-566.

Williams SR, Fletcher LN (2019) A dendritic substrate for the cholinergic control of neocortical output neurons. Neuron 101:486-499.e4.

Xiang Z, Huguenard JR, Prince DA (1998) Cholinergic switching within neocortical inhibitory networks. Science 281:985-988.

Xu M, Chung S, Zhang S, Zhong P, Ma C, Chang WC, Weissbourd B, Sakai N, Luo L, Nishino S, Dan Y (2015) Basal forebrain circuit for sleep-wake control. Nat Neurosci 18:1641-1647.

Yamasaki M, Matsui M, Watanabe M (2010) Preferential localization of muscarinic M1 receptor on dendritic shaft and spine of cortical pyramidal cells and its anatomical evidence for volume transmission. J Neurosci 30:4408-4418.

Yang C, Thankachan S, McCarley RW, Brown RE (2017) The menagerie of the basal forebrain: how many (neural) species are there, what do they look like, how do they behave and who talks to whom? Curr Opin Neurobiol 44:159-166.

Yu AJ, Dayan P (2002) Acetylcholine in cortical inference. Neural Netw 15:719-730.

Yu AJ, Dayan P (2005) Uncertainty, neuromodulation, and attention. Neuron 46:681-692.

Zaborszky L, Hoemke L, Mohlberg H, Schleicher A, Amunts K, Zilles K (2008) Stereotaxic probabilistic maps of the magnocellular cell groups in human basal forebrain. Neuroimage 42:1127-1141.

Zaborszky L, Duque A, Gielow M, Gombkoto P, Nadasdy Z, Somogyi J (2015a) Organization of the basal forebrain cholinergic projection system: Specific or diffuse? In: The rat nervous system (Paxinos G, ed), pp 491-507. San Diego: Academic.

Zaborszky L, Csordas A, Mosca K, Kim J, Gielow MR, Vadasz C, Nadasdy Z (2015b) Neurons in the basal forebrain project to the cortex in a complex topographic organization that reflects corticocortical connectivity patterns: an experimental study based on retrograde tracing and 3D reconstruction. Cereb Cortex 25:118-137.

Zant JC, Kim T, Prokai L, Szarka S, McNally J, McKenna JT, Shukla C, Yang C, Kalinchuk AV, McCarley RW, Brown RE, Basheer R (2016) Cholinergic neurons in the basal forebrain promote wakefulness by actions on neighboring non-cholinergic neurons: an opto-dialysis study. J Neurosci 36:2057-2067. 